\title{
Photocatalytic Microfluidic Reactors Utilizing Titania Nanotubes on Titanium Mesh for Degradation of Organic and Biological Contaminants
}

\author{
Harikrishnan Jayamohan ${ }^{\mathrm{a}}$, York R. Smith ${ }^{\mathrm{b}, *}$, Bruce K. Gale ${ }^{\mathrm{a}}$, Swomitra K. \\ Mohanty $^{\mathrm{c}}$, Manoranjan Misra ${ }^{\mathrm{b}}$ \\ ${ }^{a}$ Department of Mechanical Engineering, University of Utah, Salt Lake City, Utah, 84112, \\ USA \\ ${ }^{b}$ Department of Metallurgical Engineering, University of Utah, Salt Lake City, Utah, 84112, \\ USA \\ ${ }^{c}$ Department of Chemical Engineering, University of Utah, Salt Lake City, Utah, 84112, \\ $U S A$
}

\begin{abstract}
Microfluidic reactors have gained considerable interest for photocatalytic degradation of contaminants in water. These systems have advantages such as large surface-area-to-volume ratio and high control of fluid flow, yet still suffer from drawbacks due to limited mass transport associated with laminar flow. The use of titania nanotubes synthesized on a mesh substrate show improved photocatalytic performance in comparison to nanotubes synthesized on a foil substrate in a microreactor. At the lowest flow rate $(25 \mu \mathrm{L} / \mathrm{min})$, the area normalized fractional conversion of methylene blue increased from $20 \%$ for foil to $46 \%$ in the case of nanotubes on mesh. The enhanced photocatalytic performance of the mesh is due to shorter diffusion distance and induction of flow perturbation. Also, the radially outward oriented nanotubes formed over the circumference of the titanium wire leads to the efficient capture of both reflected and refracted light. The device was also applied for inactivation of E. coli O157:H7. At a flow rate of $50 \mu \mathrm{L} / \mathrm{min}$, the titania nanotubes on a mesh microreactor was able to achieve $>99 \%$ inactivation of $E$. coli under AM $1.5\left(\approx 100 \mathrm{~mW} / \mathrm{cm}^{2}\right)$ simulated solar light.
\end{abstract}

\footnotetext{
${ }^{*}$ Corresponding author

Email address: york.smith@utah.edu (York R. Smith)
}

Preprint submitted to Journal of ${ }^{A} T_{E} X$ Templates

December 7, 2015

(C) 2015. This manuscript version is made available under the Elsevier user license http://www.elsevier.com/open-access/userlicense/1.0/ 
Keywords: Microfluidics, Titania Nanotubes, Photocatalysis, E. coli inactivation

\section{Introduction}

2

According to estimates, 1.2 billion people lack access to safe drinking water, which contributes to the death of 3900 children daily 1 . Hence, access to clean water is a worldwide concern. In both industrialized and developing nations, chemical and biological contaminants are finding their way into water bodies due to increasing human activity 1. Cleanup and reuse of polluted wastewater is an attractive solution to some of these issues. Low-cost and high-efficiency water remediation technologies are needed to achieve the same 2 . Conventional wastewater treatment technologies such as adsorption or coagulation merely concentrate the pollutants present by transferring them to other phases [2 . Other conventional methods such as sedimentation, filtration, chemical, and membrane technologies are expensive and potentially generate toxic secondary pollutants [1].

Advanced Oxidation Processes (AOP) could solve some of the issues associated with conventional water treatment methods. These processes work by the generation of transitory highly reactive oxygen species (ROS) for mineralization of chemical and biological pollutants present in water [2. Among these AOPs, photocatalytic environmental remediation employing semiconductor photocatalysts has been widely applied for water-based pollutants [3, 2, Nanomaterial semiconductor photocatalysts have been used due to their interesting properties over bulk materials. Many studies have used powdered photocatalysts suspended in solution [4, 5]. However, the use of powdered photocatalysts necessitates their downstream recovery. This can lead to increased operational and capital costs [5, 6]. Also, the use of powdered catalyst particles limit the depth of penetration of light due to strong adsorption and scattering [7, 8]. The immobilization or growth of photocatalysts as a film on a substrate eliminates many of these drawbacks [6]. 
Microfluidic reactors (microreactors) have been increasingly applied to water remediation over conventional macroscale reactors [9, 10]. This is because conventional macroscale reactors have limitations due to mass transport and poor photon management [5]. In the case of microreactors, the thin layer of liquid over the catalyst ensures lesser photons are lost due to scattering [1]. Microreactors can be advantages over conventional macroscale reactors due to large surface to volume ratio, smaller diffusion distance, and large mass transfer efficiency 12. Microfluidic photocatalytic reactors have been reported to have higher photocatalytic efficiency compared to conventional reactors [10. Current microfluidic formats face a major drawback due to limited mass-transport associated with laminar flow [5]. To overcome this limitation, Li et al. reported the use of a fiberglass coated with P25 titanium dioxide nanoparticle (TNP) layer for the degradation of methylene blue (MB) [5]. The new design, incorporating the same catalyst (TNP), but on a geometrically different substrate (fiber) yielded higher degradation over a conventional microreactor platform involving P25 TNP layer embedded on a flat surface.

Titanium dioxide $\left(\mathrm{TiO}_{2}\right)$ has been widely applied to photocatalytic degradation of chemical and biological pollutants [13, 6, 14, 15. Titania nanotube arrays (TNA) are of particular interest due to their simple synthesis and improved ability to transport photogenerated charges as compared to their TNP counterpart [16]. Titania nanotube arrays have shown to have enhanced photocatalytic properties compared to TNP layers in a macroscale batch reactor configuration [17. Further, by electrochemical anodization, TNA can be synthesized on different titanium (Ti) metal substrates, having varied geometries (e.g., thin wires [8], meshes [16], and curved surfaces [18]).

$\mathrm{TiO}_{2}$ based catalysts in the form of TNA 11] and TNP [19, 10, 5] have been applied in microreactors for photocatalytic degradation. We recently reported the application of TNA synthesized on a foil $\left(\mathrm{TNA}_{\text {foil }}\right)$ for degradation of MB in a microreactor 11. The $\mathrm{TNA}_{\text {foil }}$ had enhanced photocatalytic performance over P25 TNP layer when used in a microfluidic format.

Although $\mathrm{TNA}_{\text {foil }}$ has shown promising results for photocatalytic applica- 
tions, the use of metal foils has limitations (such as the opacity, inefficient use of $\mathrm{Ti}$, and reduced flexibility). As an alternative, metal meshes provide an approach that allows for high flexibility, efficient Ti utilization, and transparency. Such a format has shown to be effective in applications such as dye-sensitized solar cells [20].

We report the use of TNA grown on a Ti mesh $\left(\mathrm{TNA}_{m e s h}\right)$ for photocatalytic degradation of $\mathrm{MB}$ and inactivation of E. coli O157:H7 in a microfluidic format. The microfluidic device was fabricated using non-cleanroom based technique which makes it suitable for large scale applications 21. The degradation performance is compared to that of previously reported data using $\mathrm{TNA}_{\text {foil }}$ at different flow rates in a geometrically similar microreactor[11. We also report the use of $\mathrm{TNA}_{m e s h}$ for the photocatalytic inactivation of E. coli. $\mathrm{TiO}_{2}$ based photocatalysts have been shown to have bactericidal and bacterial endotoxin decomposing capability 22, 23, 24, 14. The use of TNA for inactivation of pathogens in a flow through system has yet to be fully explored.

\section{Experimental}

\subsection{Preparation and characterization of TNA on foil and mesh}

Titania nanotube arrays grown on a titanium mesh were synthesized by electrochemical anodization similar to an earlier reported protocol [16]. In short, Ti gauze (50 mesh woven from $0.102 \mathrm{~mm}$ diameter wire, $64 \%$ open area) was obtained from Alfa Aesar and cut into $3 \times 2 \mathrm{~cm}^{2}$ dimensions. The Ti gauze was first washed with isopropanol and DI water under sonication for 10 mins each, and then electropolished in $1^{\circ} \mathrm{C}$ glacial acetic acid/perchloric acid (9:1 volume ratio) at $60 \mathrm{~V}$ under sonication for $1 \mathrm{~min}$ [25]. The electrochemical anodization was carried out at an applied potential of $60 \mathrm{~V}$ (D.C.)(Agilent, E3647A) for 60 minutes. The thus formed $\mathrm{TNA}_{m e s h}$ was rinsed with DI water, air dried and subsequently annealed in an atmosphere of $\mathrm{N}_{2}+2 \% \mathrm{H}_{2}$ at $500{ }^{\circ} \mathrm{C}\left(1.6{ }^{\circ} \mathrm{C} / \mathrm{min}\right.$ ramp rate) for $2 \mathrm{~h}$. The morphology of the thus formed TNA $\mathrm{T}_{\text {mesh }}$ film was characterized using a field emission scanning electron microscope (SEM) (Hitachi, 
S-4800).

\subsection{Fabrication of microfluidic channel and integration of TNAmesh substrate}

The microfluidic device was fabricated by soft lithography 21] similar to that reported in our earlier study[1]. In short, the mold was cut on a tape using a laser. Next, a polydimethylsiloxane (PDMS) mixture was poured onto the mold, and cured in an oven to create the PDMS layer. Subsequently, inlet and outlet channels were bored onto the PDMS channel and the $\mathrm{TNA}_{m e s h}$ catalyst was embedded into the PDMS channel. Finally, a corona activated glass slide was bonded to the PDMS layer. A photograph of the microfluidic reactor is provided in the Supporting information (Fig. S1).

\subsection{Evaluation of the photocatalytic degradation of methylene blue}

The photocatalytic degradation of the device was evaluated using MB as a model pollutant. MB is a non-biodegradable dye and is used for characterizing photocatalytic performance [26, 27, 17]. The experimental setup used to evaluate the photocatalytic performance of the device is depicted in our earlier work 11. In a typical experimental run, $5 \mathrm{ml}$ of $18 \mathrm{mM}$ aqueous solution of $\mathrm{MB}$ was injected through the inlet into the microfluidic device using a syringe pump (KD Scientific, Manassas, VA) via Tygon tubing (0.02 inch/0.0508 mm inner diameter) at different flow rates ranging from $25-200 \mu \mathrm{L} / \mathrm{min}$. The microfluidic device was irradiated with AM 1.5 simulated solar light $\left(\approx 100 \mathrm{~mW} / \mathrm{cm}^{2}\right)$. The intensity of the light was measured at the surface of the microfluidic device using a handheld power meter (Nova, Ophir-Spiricon, UT). The degraded MB solution was collected and the concentration was determined by monitoring the change in characteristic absorption peak at $\lambda=664 \mathrm{~nm}$ using a UV-vis spectrophotometer (Shimadzu Corp., Japan). The fractional conversion was calculated by:

$$
X(\%)=\frac{\mathrm{A}_{0}-\mathrm{A}}{\mathrm{A}_{0}} 100
$$

where $\mathrm{A}_{0}$ is the initial concentration absorbance value, and $\mathrm{A}$ is the absorbance value of the degraded solution. The experiment was repeated in the 
absence of AM 1.5 light to evaluate the amount of MB adsorbed on the catalyst. The fractional conversion was normalized with respect to the substrate area exposed to normal incident light [8]. The results were compared to normalized fractional conversion of $\mathrm{MB}$ using a $\mathrm{TNA}_{\text {foil }}(12 \mu \mathrm{m}$ and $7 \mu \mathrm{m}$ nanotube lengths) reported in our earlier work[11].

\subsection{Evaluation of the photocatalytic inactivation of E. coli}

The photocatalytic inactivation of $E$. coli was evaluated using $\mathrm{TNA}_{m e s h}$ in a microreactor as described above. E. coli O157:H7 (non-pathogenic strain, Catalog no. 700728, ATCC) was used to prepare different concentrations (1000 and $10000 \mathrm{CFUs} / \mathrm{mL}$ ) of $E$. coli in $1 \mathrm{X}$ PBS solution 28. The concentration range of $E$. coli was chosen based on total coliform levels in municipal wastewater 29]. The experimental setup is the same as that for MB degradation mentioned previously. A $4 \mathrm{~mL}$ sample of the $E$. coli solution was taken in a syringe, $3 \mathrm{~mL}$ of which was injected using a syringe pump through the inlet into the microfluidic device. The flow rates were varied from $25-200 \mu \mathrm{L} / \mathrm{min}$ in the absence and presence of AM 1.5 simulated solar light $\left(\approx 100 \mathrm{~mW} / \mathrm{cm}^{2}\right)$. The intensity of the light was varied from $10-100 \mathrm{~mW} / \mathrm{cm}^{2}$ to evaluate the effect on inactivation. The inactivated E. coli solution was collected and plated on agar (Difco Nutrient Agar, Catalog no. 213000, Becton Dickinson, Sparks, MD), incubated at $37^{\circ} \mathrm{C}$ for 12 hours and subsequently counted to calculate the final concentration $\left(\mathrm{C}_{f}\right)$. The $1 \mathrm{~mL}$ stock solution left in the syringe was also plated after the experimental run (to avoid any non-photocatalytic, room temperature based inactivation of E. coli during the experimental run) to determine the initial concentration $\left(\mathrm{C}_{0}\right)$. The survival ratio (S.R) was calculated by:

$$
\operatorname{S.R}(\%)=\frac{\mathrm{C}_{\mathrm{f}}}{\mathrm{C}_{0}} 100
$$

where $\mathrm{C}_{f}$ is the final concentration $(\mathrm{CFU} / \mathrm{mL})$ of $E$. coli post inactivation in the microfluidic device, and $\mathrm{C}_{0}$ is the initial concentration $(\mathrm{CFU} / \mathrm{mL})$ of $E$. coli (solution left in the syringe). The experiment was repeated in the absence of AM 1.5 light to evaluate the amount of $E$. coli adsorbed/trapped in the 


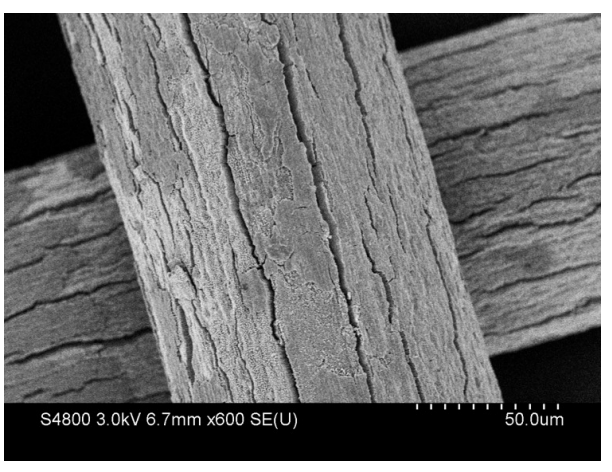

(a)

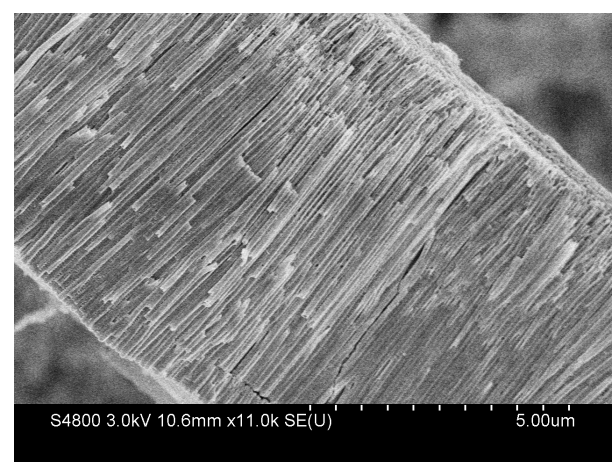

(b)

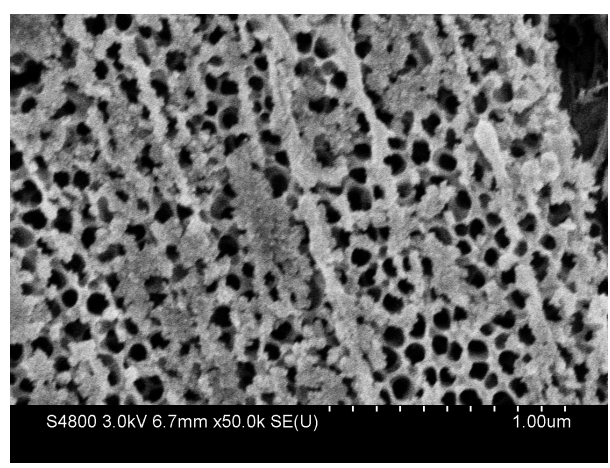

(c)

Figure 1: SEM images of $\mathrm{TNA}_{m e s h}$ anodized at $60 \mathrm{~V}$ for 1 hour, showing the (a) low-magnified overall image of nanotubes on the anodized mesh, (b) sidewall, and (c) top morphology.

catalyst. The experiment was also performed in the presence of AM 1.5 light in the microreactor without the catalyst embedded in it to evaluate the effect of light inactivation only on $E$. coli.

\section{Results and discussion}

\subsection{Properties of Titania nanotubes}

The morphology of the $\mathrm{TNA}_{\text {mesh }}$ was characterized by SEM. Fig. 1 1 shows

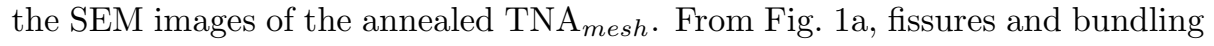
of nanotubes are observed in $\mathrm{TNA}_{\text {mesh }}$ (unlike TNA formed on a planer substrate/TNA foil). 
These are due to the curvature-induced stress during the formation of nanotubes and the outward radial growth of the nanotubes on a curved Ti substrate [8, 20]. Such a morphology is observed in TNA formed on wire-type substrates 30. The TNA $_{m e s h}$ nanotube length is approximately $8 \mu \mathrm{m}$ (1 hour anodization). The $\mathrm{TNA}_{\text {mesh }}$ tubes have an approximate inner diameter of $80 \mathrm{~nm}$ and wall thickness in the range $10-15 \mathrm{~nm}$. Though the orientation of nanotubes differ, the morphology (nanotube height and diameter) of the $\mathrm{TNA}_{m e s h}$ is similar to the $\mathrm{TNA}_{\text {foil }}[1]$.

\subsection{Normalized degradation efficiency (MB) of the microfluidic reactor- Effect of flow rates}

The results of the degradation at different flow rates over $\mathrm{TNA}_{\text {mesh }}(8 \mu \mathrm{m})$ vs. TNA $_{\text {foil }}(12 \mu \mathrm{m}$ and $7 \mu \mathrm{m})$ with AM 1.5 irradiation are presented in Fig. 2 . It is evident that the normalized fractional conversion using TNA $_{m e s h}$ is higher than $\mathrm{TNA}_{\text {foil }}$, in the flow range under consideration $(25-200 \mu \mathrm{L} / \mathrm{min})$. Both the $\mathrm{TNA}_{m e s h}$ and $\mathrm{TNA}_{\text {foil }}$ catalysts show similar trends in a decrease in degradation in the $25-50 \mu \mathrm{L} / \mathrm{min}$ domain. This is intuitive since an increase in flow rate would result in less time for the $\mathrm{MB}$ to diffuse and come in contact with the catalyst surface. However, it is interesting to note that the degradation performance of both the $\mathrm{TNA}_{m e s h}$ and $\mathrm{TNA}_{\text {foil }}$ catalysts remain constant over the $50-200 \mu \mathrm{L} / \mathrm{min}$ domain. Such a trend has been previously observed, and is primarily due to the faster generation of oxidizing species with increased flow rate 11 .

The TNA $_{\text {mesh }}(8 \mu \mathrm{m}$ tube length) shows a higher normalized fractional conversion (NFC) compared to $\mathrm{TNA}_{\text {foil }}$ in the flow domain under consideration. At the lowest flow rate $(25 \mu \mathrm{L} / \mathrm{min}), \mathrm{TNA}_{\text {mesh }}$ exhibits a NFC more than twice (2.5 times) that of $\mathrm{TNA}_{\text {foil }}$ of comparable length $(7 \mu \mathrm{m})$. Similarly at the highest flow rate $(200 \mu \mathrm{L} / \mathrm{min}), \mathrm{TNA}_{\text {mesh }}$ has a NFC 2.4 times higher than TNA $_{\text {foil }}(7 \mu \mathrm{m})$. Even in the case of longer tube geometry, TNA foil $(12 \mu \mathrm{m}$ tube length) has lower NFC than $\mathrm{TNA}_{m e s h}$. This is in spite of the fact that nanotube length on $\mathrm{TNA}_{\text {mesh }}$ is $66 \%$ lower than that on $\mathrm{TNA}_{\text {foil }}$. The length 


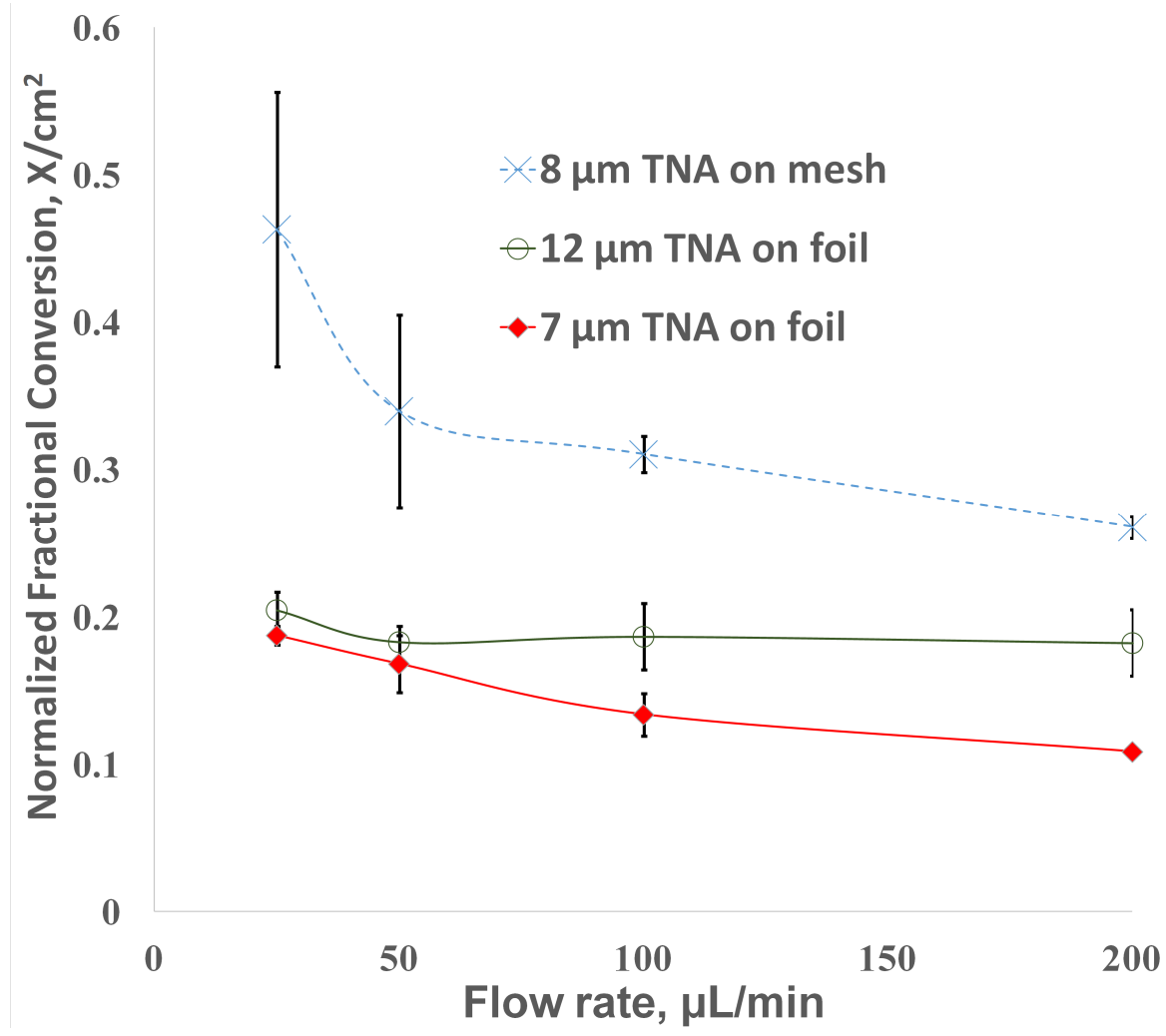

Figure 2: Effect of flow rate on MB degradation for $\mathrm{TNA}_{\text {mesh }}$ and $\mathrm{TNA}_{\text {foil }}$ catalyst in the presence of AM 1.5 light. The fractional conversion is normalized with respect to substrate area exposed to normal incident light. The data associated with 7 and $12 \mu \mathrm{m}$ is from ref. 11 . 


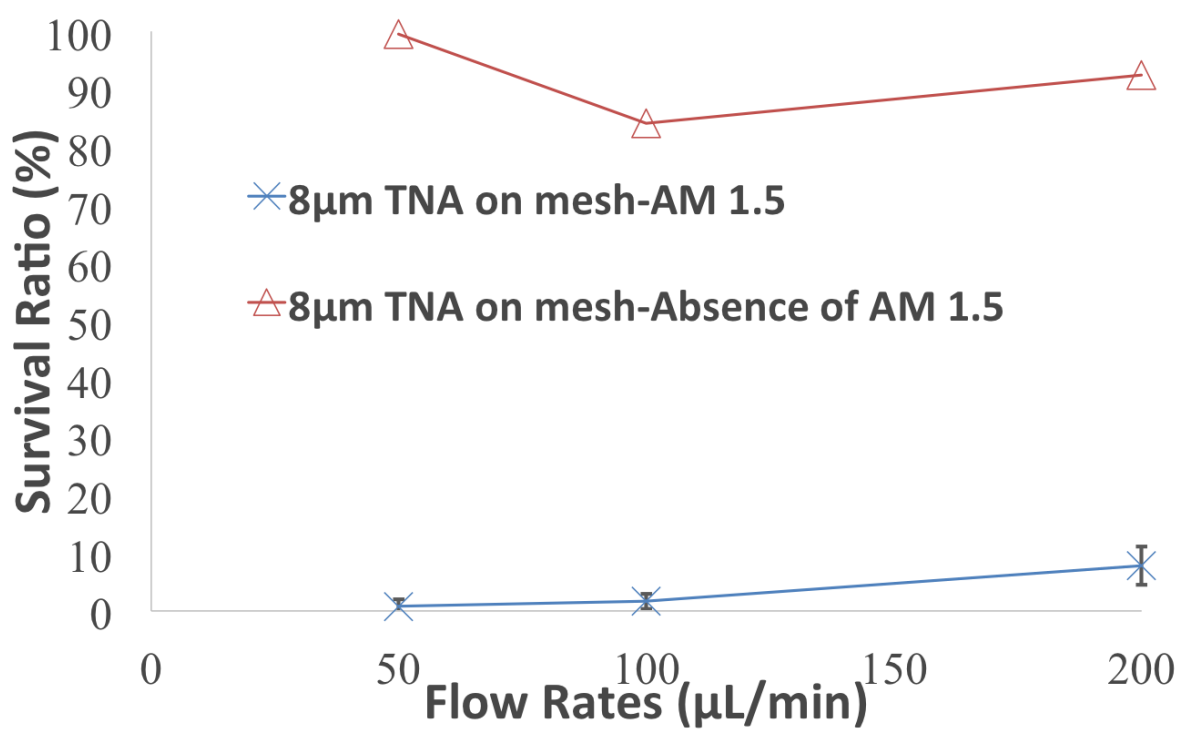

Figure 3: Effect of flow rate on E. coli inactivation for $\mathrm{TNA}_{m e s h}(8 \mu \mathrm{m}$ length $)$ in the presence and absence of AM 1.5 light (1000 CFU/mL starting concentration).

of the nanotubes is reported to have an effect on the fractional conversion of MB in microfluidic reactors [1].

\subsection{Inactivation (E. coli)- Effect of flow rates}

The results of the inactivation of E. coli at different flow rates over TNA mesh are presented in Fig. 3 and Fig. 4 In the absence of AM 1.5 light, it is evident that in the given flow range $(50-200 \mu \mathrm{L} / \mathrm{min})$ there is little inactivation (S.R 84-99.5\%) of E. coli due to adsorption by the catalyst. Also, at the lowest flow rate $(50 \mu \mathrm{L} / \mathrm{min})$, there is little inactivation (S.R $>92 \%$ ) of $E$. coli under visible light illumination in the absence of $\mathrm{TNA}_{\text {mesh }}$ catalyst (not shown). This indicates that the inactivation is primarily due to photocatalytic generation of ROS species by $\mathrm{TiO}_{2}$ and not due to the inactivation by the UV component of light. This has been previously established for batch reactor systems applied to E. coli inactivation 31, 32.

For a $1000 \mathrm{CFUs/mL} \mathrm{starting} \mathrm{concentration,} \mathrm{at} \mathrm{the} \mathrm{lowest} \mathrm{flow} \mathrm{rate} \mathrm{(50}$ $\mu \mathrm{L} / \mathrm{min}$ ), almost $100 \%$ of the $E$. coli is inactivated using the $\mathrm{TNA}_{\text {mesh }}$ catalyst. 


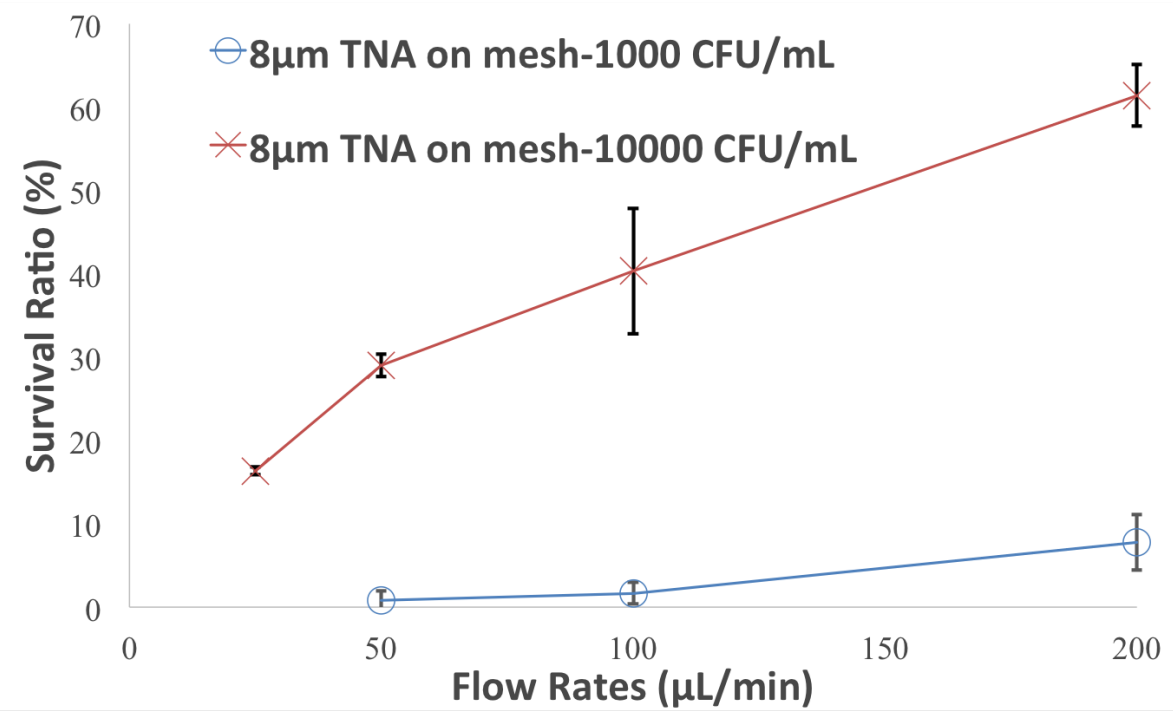

Figure 4: Effect of flow rate on E. coli inactivation at different starting concentration for TNA $_{m e s h}$ in the presence of AM 1.5 light.

Even, at the highest flow rate more than $92 \%$ of $E$. coli is inactivated. As the starting concentration increases by a order of magnitude, the S.R increases from $<1 \%$ to $6 \%$ (Fig. 4). Although, the principle of photocatalytic degradation of both MB and E. coli are similar viz. by degradation by ROS, the actual rate of degradation will be different due to differences in diffusion coefficient between the two. In addition, $E$. coli is a straight rod shaped organism $(\approx 0.5 \mu \mathrm{m}$ in width by $2 \mu \mathrm{m}$ in length), consisting of complex structures of lipopolysaccharide, a peptidoglycan cell wall, and lipid bilayers of inner and outer membranes, etc 33 .

Due to the complex nature of photocatalytic inactivation of microbes, often times empirical expressions are used to describe the overall kinetics. One of the most commonly used models for photocatalytic inactivation of microbes is the Chick-Watson model 34, 35]. A modified Chick-Watson model[36, 37](Eqn. 3) was used to describe the overall kinetics with respect to residence time $(\tau)$ for E. coli concentrations of 1000 and $10000 \mathrm{CFU} / \mathrm{mL}$. The model was fit with the experimental data using a non-linear fitting routine (OriginPro ${ }^{\circledR}$ ): 


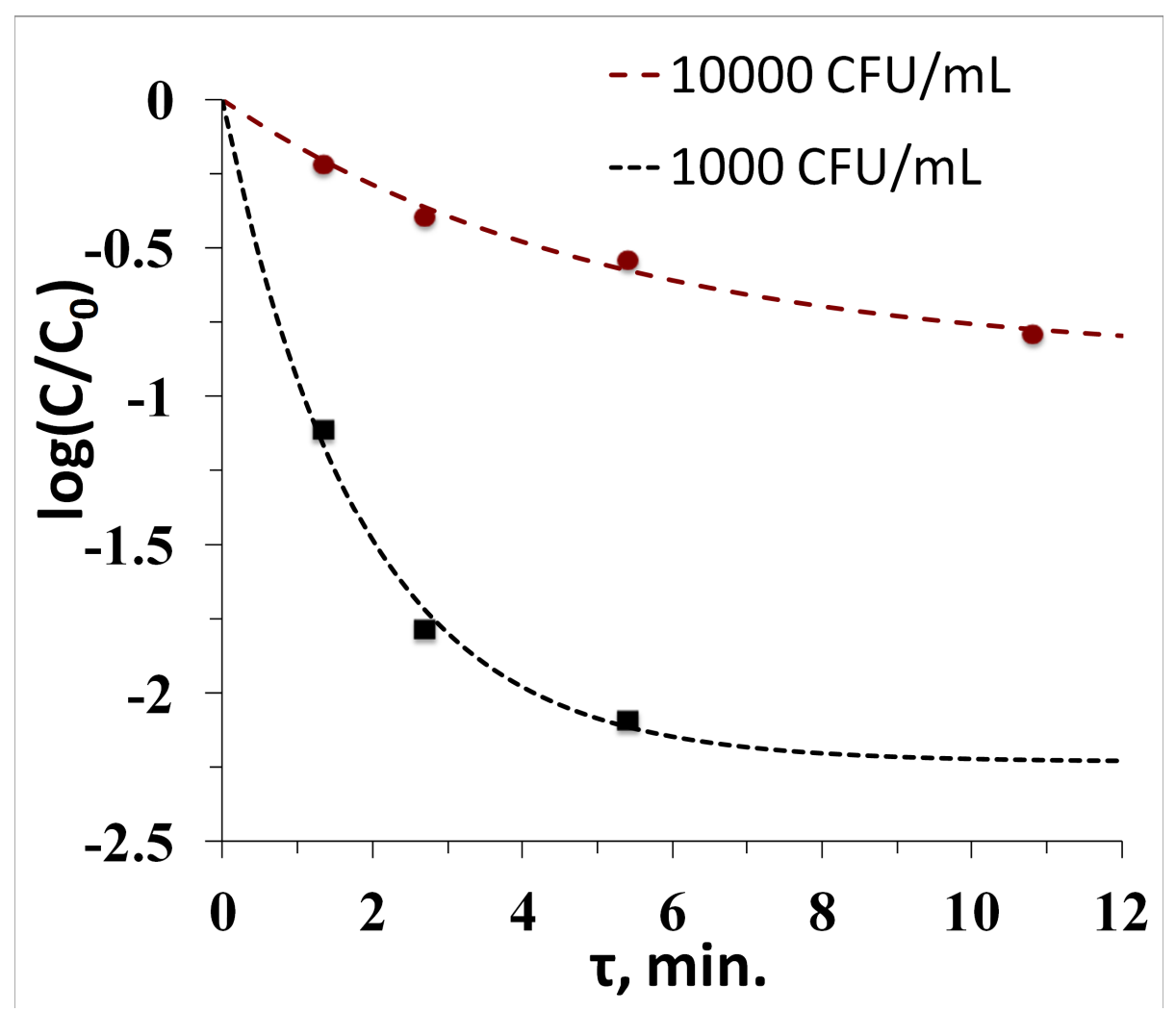

Figure 5: Kinetics with respect to residence time $(\tau)$ for E. coli concentrations of 1000 and $10000 \mathrm{CFU} / \mathrm{mL}$.

$$
\log \frac{C_{t}}{C_{0}}=k_{1}\left[1-e^{-k_{2} \tau}\right]
$$

where $\mathrm{C}_{t}$ is the $E$. coli concentration $(\mathrm{CFU} / \mathrm{ml})$ at time $t$. The modified Chick-Watson model was found to have good agreement with the experimental data (Fig. 5). The parameters, $\mathrm{k}_{1}$ and $\mathrm{k}_{2}$ for $1000 \mathrm{CFU} / \mathrm{mL}$ were found to be $-2.23 \pm 0.132$ and $0.544 \pm 0.083 \mathrm{~min}^{-1}$, respectively, with an adjust $\mathrm{R}^{2}$ value of 0.96993 and $\chi^{2}=0.00754$. For $10000 \mathrm{CFU} / \mathrm{mL}$ E. coli concentration, the parameters $\mathrm{k}_{1}$ and $\mathrm{k}_{2}$ were found to be $-0.8794 \pm 0.0747$ and $0.1966 \pm 0.0343 \mathrm{~min}^{-1}$, respectively, with an adjust $\mathrm{R}^{2}$ value of 0.9794 and $\chi^{2}=0.00121$. 


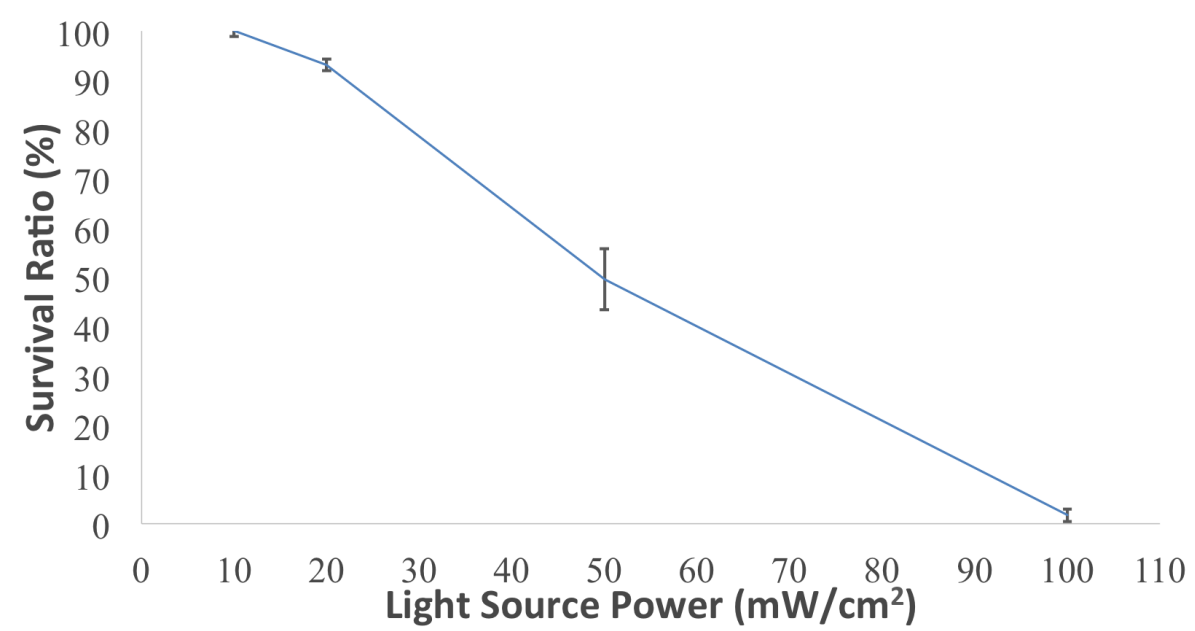

Figure 6: Effect of light intensity on E. coli degradation for TNA $\mathrm{Tesh}_{\text {es }}(1000 \mathrm{CFU} / \mathrm{mL}$ starting concentration, $100 \mu \mathrm{L} / \mathrm{min}$ flow rate).

\subsection{Inactivation efficiency of E. coli- Effect of light intensity}

With a decrease in light intensity, there is commensurate drop in E. coli inactivation. A $50 \%$ decrease in light intensity $\left(50 \mathrm{~mW} / \mathrm{cm}^{2}\right)$ results in a $50 \%$ drop in inactivation. From the Fig. 6, their appears to be a linear relationship between inactivation rate and light intensity. This indicates the process is reaction dominated 38 , i.e. the process has not reached a limiting light intensity where the electron-hole pair recombination limits a further increase in inactivation. This means by further increasing the light intensity, the inactivation rate can be increased or a higher flow rate/process throughput can be achieved (at a given inactivation rate) till a certain limiting point 38. This could be due to the low light scattering observed in the case of $\mathrm{TNA}_{m e s h}$ format.

\subsection{Discussion}

The mechanism of photocatalytic MB degradation is well reported in literature [3, 17]. The MB dye molecules adsorbed on the surface of the catalyst are oxidized by the photoinduced holes generated by the $\mathrm{TiO}_{2}$ catalyst to form a radical $\bullet^{\bullet} \mathrm{MB}^{+}$. These radicals further react with $\mathrm{O}_{2}$ to form $[\mathrm{MBOO}]^{+}$. Subse- 


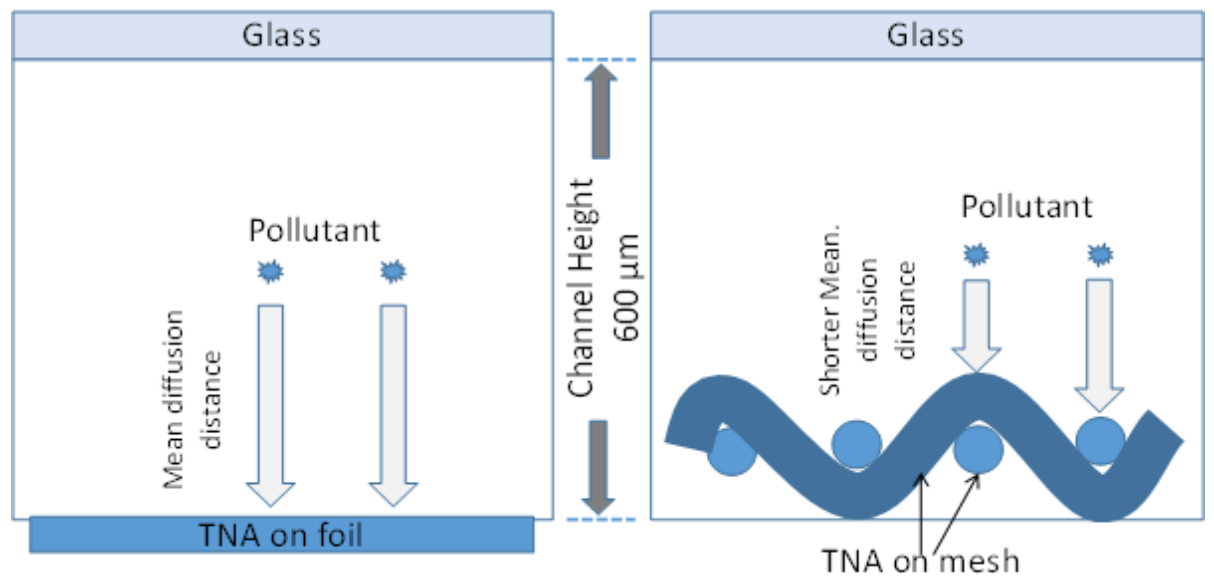

Figure 7: $\mathrm{TNA}_{\text {foil }}$ and $\mathrm{TNA}_{\text {mesh }}$ catalyst layouts in the microfluidic channel illustrating the shorter diffusion path using a mesh substrate.

quently the heteropolyaromatic ring is broken, and degradation occurs [39]. It is important to mention that previous investigations have studied the visible light activity of TNA [40, 41]. The visible light activity of TNA can be attributed to doped carbon sourced from ethylene glycol in the anodization bath 42, 41].

Titania nanotubes formed on titanium wires have been reported to demonstrate higher dye degradation performance in comparison to $\mathrm{TNA}_{\text {foil }}$ using a conventional macroscale batch reactor 8 . The higher degradation of the former was attributed to the geometry wherein the wires are juxtaposed next to one another. Also, on a wire or mesh substrates, titania nanotubes grow radially outwards in a uniform and compact manner. Such a configuration, enables them to not only to utilize the absorbed light, but also the reflected and refracted light as well[8]. In the case of a microfluidic format, the enhanced photocatalytic degradation of $\mathrm{MB}$ using the $\mathrm{TNA}_{\text {mesh }}$ catalyst can be attributed to a shorter mass transport length [5]. Unlike in the case of $\mathrm{TNA}_{\text {foil }}$, the $\mathrm{TNA}_{\text {mesh }}$ catalyst remains suspended across height of the channel (Fig. 7). Hence, the MB molecules do not have to diffuse all the way to bottom of the microfluidic channel to reach the catalyst surface. The differences in the substrate geometry enable better access of the pollutant molecules to the catalyst surface. This principle 


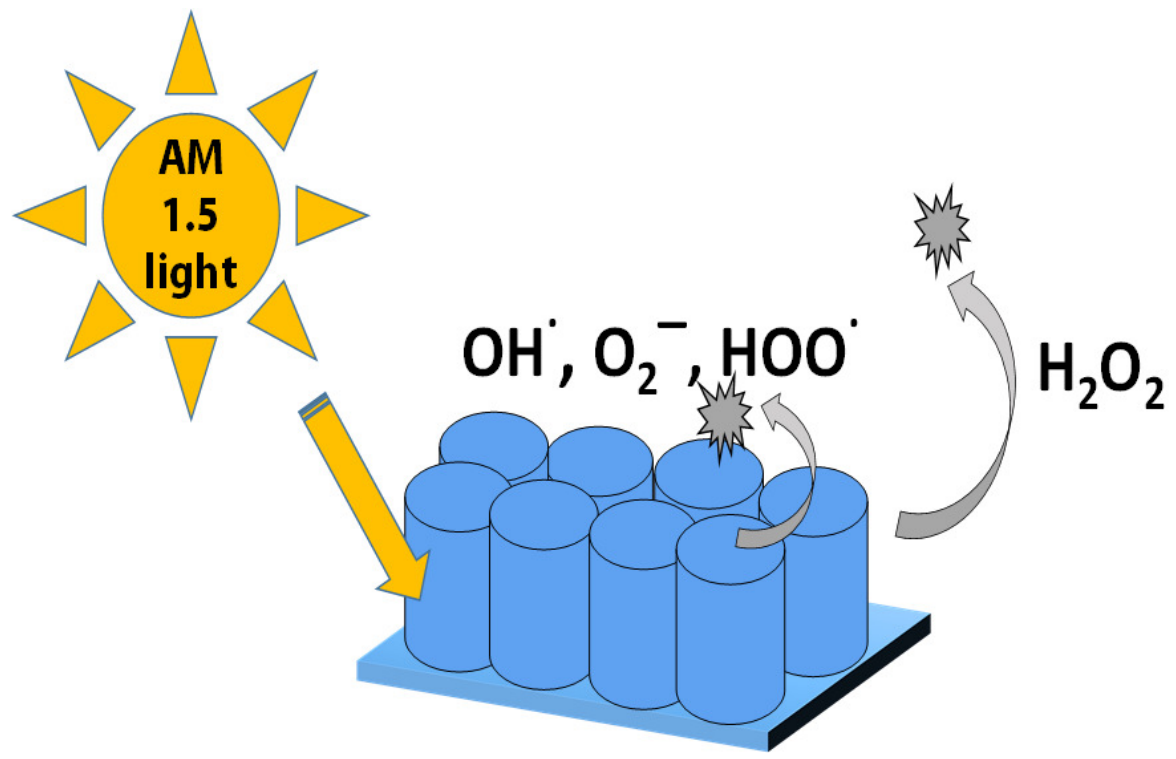

Figure 8: Degradation scheme of E. coli/MB by ROS generated by TNA catalyst. The lifetime of $\mathrm{ROS}$ like $\mathrm{OH}^{\bullet}, \mathrm{O}_{2}^{-}, \mathrm{HOO}^{\bullet}$ is short and can only degrade pollutants at surface of the catalyst. $\mathrm{H}_{2} \mathrm{O}_{2}$ molecules are more stable and diffuse from the catalyst surface to pollutants present in the bulk solution [31. 
has been utilized in earlier studies, immobilizing TNP catalyst on fiberglass (as compared to a planar surface) to enhance mass transport [5]. Thus the mass transport is enhanced in the case of $\mathrm{TNA}_{\text {mesh }}$ in comparison to $\mathrm{TNA}_{\text {foil }}$. This is especially critical in microfluidic formats wherein the mass transport is limited due to the laminar nature of the flow. Another reason for the enhanced performance can be attributed to the flow perturbation induced by the mesh [5]. In our previous work on degradation of $\mathrm{MB}$ using $\mathrm{TNA}_{\text {foil }}$ in microreactors, we show that the diffusion has a higher effect on fractional conversion than rate constant [1]. Since the use of $\mathrm{TNA}_{m e s h}$ results in an enhanced diffusivity (shorter mass transport length), the enhanced fractional conversion of MB by $\mathrm{TNA}_{\text {mesh }}$ over $\mathrm{TNA}_{\text {foil }}$ can also be attributed to the same.

The application of $\mathrm{TiO}_{2}$ photocatalysts for $E$. coli inactivation was first reported by Yoshihiko et al. 31]. The mechanism of degradation of bacteria is similar to that for $\mathrm{MB}$ viz. due to the generation of $\mathrm{ROS}\left(\mathrm{OH}^{\bullet}, \mathrm{O}_{2}^{-}, \mathrm{HOO}^{\bullet}\right.$, $\left.\mathrm{H}_{2} \mathrm{O}_{2}\right)$ by TNA 43,33 . The photo generated hole sites in the valance band of titania reacts with water to form hydroxyl radicals $\left(\mathrm{OH}^{\bullet}\right)$, while the electrons promoted to the conduction band react with molecular oxygen to form superoxide ions and $\mathrm{H}_{2} \mathrm{O}_{2}$. These further react with water to form additional hydroxl radicals (Fig. 8). An alternative mechanism, involving the direct oxidation of bacteria through the photogenerated holes has been ruled out 23]. The photogenerated radicals are responsible for the inactivation of bacteria, by oxidizing organic material up to complete mineralization [23, 14]. The generated radicals attack the bacterial cell wall, leading to cell wall rupture 22, 23. This cause the degradation of lipopolysaccharide, a cell wall constituent and promote peroxidation of the lipid membrane 24,44 . This results in the increase in the permeability of cells, the leakage of intracellular molecules, penetration of ROS into the cytoplasmic inner membrane, and finally induces bacterial cell death 32$]$. The inactivation of the bacteria could generate pyrogenic and toxic ingredients such as endotoxins. Endotoxins are the lipopolysaccharide cell wall constituents of Gram-negative bacteria like E. coli. But $\mathrm{TiO}_{2}$ based photocatalysis have shown to have deactivating effect on endotoxins [24]. The quantification of the de- 
activating effect of TNA based photocatalysts on endotoxins in a microfluidic reactor will be the subject of future work. The use of microfluidic photocatalytic systems involving $\mathrm{TNA}_{m e s h}$ could be used to harvest clean and inexpensive energy from the sun for photocatalytic water remediation. While high-throughput applications can be a challenge due to lower volume of solutions involved with microreactors, they can be resolved by scaling up the microreactors [45]. These could also be used as portable water treatment devices especially in developing countries. The technique could be also be used in conjunction with current ultraviolet purifiers, wherein the power consumption can be significantly reduced, or the time for effective water treatment can be significantly reduced.

\section{Conclusion}

The photocatalytic degradation performance using $\mathrm{TNA}_{m e s h}$ and $\mathrm{TNA}_{\text {foil }}$ catalyst in a microreactor was compared at different flow rates under simulated AM 1.5 light. The experimental results show that, $\mathrm{TNA}_{m e s h}$ exhibited enhanced degradation (area normalized) of MB pollutant in comparison $\mathrm{TNA}_{\text {foil }}$. The enhanced performance of $\mathrm{TNA}_{m e s h}$ over $\mathrm{TNA}_{\text {foil }}$ is due to shorter diffusion distance and induction of flow perturbation, along with the efficient capture of both reflected and refracted light in the case of former. The morphology of the individual nanotubes on both the $\mathrm{TNA}_{m e s h}$ and $\mathrm{TNA}_{\text {foil }}$ substrate is similar. It is the orientation of nanotubes on the two substrates that account for the difference in the photocatalytic performance. The microreactor was applied to the inactivation of E. coli O157:H7. The the TNA $_{m e s h}$ microreactor was able to achieve $>99 \%$ inactivation of $E$. coli at a flow rate of $50 \mu \mathrm{L} / \mathrm{min}(\approx 100$ $\mathrm{mW} / \mathrm{cm}^{2} \mathrm{AM} 1.5$ light). The device can be used as an integrated platform for degradation of an array of organic and biological contaminants. The device can also be integrated with a biological or organic pollutant quantification unit which can enable real-time optimization of the flow rate/throughput based on amount of pollutant present. 


\section{Acknowledgments}

The work presented here was supported by the Utah Science Technology and Research (USTAR) initiative. YRS acknowledges support in part by the U.S. Department of Energy, EERE SunShot Postdoctoral Research Award.

\section{References}

[1] M. A. Shannon, P. W. Bohn, M. Elimelech, J. G. Georgiadis, B. J. Mariñas, A. M. Mayes, Science and technology for water purification in the coming decades, Nature 452 (7185) (2008) 301-310.

[2] M. N. Chong, B. Jin, C. W. Chow, C. Saint, Recent developments in photocatalytic water treatment technology: A review, Water Res. 44 (10) (2010) 2997-3027.

[3] H. Lachheb, E. Puzenat, A. Houas, M. Ksibi, E. Elaloui, C. Guillard, J.-M. Herrmann, Photocatalytic degradation of various types of dyes (Alizarin S, Crocein Orange G, Methyl Red, Congo Red, Methylene Blue) in water by UV-irradiated titania, Appl. Catal., B: Environ. 39 (1) (2002) 75-90.

[4] R. W. Matthews, Photo-oxidation of organic material in aqueous suspensions of titanium dioxide, Water Res. 20 (5) (1986) 569-578.

[5] L. Li, R. Chen, X. Zhu, H. Wang, Y. Wang, Q. Liao, D. Wang, Optofluidic microreactors with TiO2-coated fiberglass, ACS Appl. Mater. Interfaces 5 (23) (2013) 12548-12553.

[6] N. Baram, D. Starosvetsky, J. Starosvetsky, M. Epshtein, R. Armon, Y. Ein-Eli, Enhanced inactivation of E. coli bacteria using immobilized porous TiO2 photoelectrocatalysis, Electrochim. Acta 54 (12) (2009) 33813386 .

[7] N. M. Mahmoodi, M. Arami, N. Y. Limaee, Photocatalytic degradation of triazinic ring-containing azo dye (Reactive Red 198) by using immobilized 
TiO2 photoreactor: Bench scale study, J. Hazard. Mater. 133 (1) (2006) $113-118$.

[8] A. Kar, Y. R. Smith, V. Subramanian, Improved photocatalytic degradation of textile dye using titanium dioxide nanotubes formed over titanium wires, Environ. Sci. Technol. 43 (9) (2009) 3260-3265.

[9] Z. Han, J. Li, W. He, S. Li, Z. Li, J. Chu, Y. Chen, A microfluidic device with integrated $\mathrm{ZnO}$ nanowires for photodegradation studies of methylene blue under different conditions, Microelectron. Eng. 111 (2013) 199-203.

[10] L. Lei, N. Wang, X. Zhang, Q. Tai, D. P. Tsai, H. L. Chan, Optofluidic planar reactors for photocatalytic water treatment using solar energy, Biomicrofluidics 4 (4) (2010) 043004.

[11] H. Jayamohan, Y. R. Smith, L. C. Hansen, S. K. Mohanty, B. K. Gale, M. Misra, Anodized titania nanotube array microfluidic device for photocatalytic application: Experiment and simulation, Appl. Catal., B: Environ. 174 (2015) 167-175.

[12] Z. Meng, X. Zhang, J. Qin, A high efficiency microfluidic-based photocatalytic microreactor using electrospun nanofibrous $\mathrm{TiO} 2$ as a photocatalyst, Nanoscale 5 (11) (2013) 4687-4690.

[13] M. R. Prairie, L. R. Evans, B. M. Stange, S. L. Martinez, An investigation of titanium dioxide photocatalysis for the treatment of water contaminated with metals and organic chemicals, Environ. Sci. Technol. 27 (9) (1993) $1776-1782$.

[14] G. Prasad, G. Agarwal, B. Singh, G. Rai, R. Vijayaraghavan, Photocatalytic inactivation of Bacillus anthracis by titania nanomaterials, J. Hazard. Mater. 165 (1) (2009) 506-510.

[15] Y. R. Smith, R. S. Ray, K. Carlson, B. Sarma, M. Misra, Self-ordered titanium dioxide nanotube arrays: Anodic synthesis and their photo/electrocatalytic applications, Materials 6 (7) (2013) 2892-2957. 
[16] Y. R. Smith, V. Subramanian, Heterostructural composites of TiO2 meshTiO2 nanoparticles photosensitized with CdS: A new flexible photoanode for solar cells, J. Phys. Chem. C 115 (16) (2011) 8376-8385.

[17] J. M. Macak, M. Zlamal, J. Krysa, P. Schmuki, Self-organized TiO2 nanotube layers as highly efficient photocatalysts, Small 3 (2) (2007) 300-304.

[18] B. Chen, K. Lu, Influence of patterned concave depth and surface curvature on anodization of titania nanotubes and alumina nanopores, Langmuir 27 (19) (2011) 12179-12185.

[19] H. Lindstrom, R. Wootton, A. Iles, High surface area titania photocatalytic microfluidic reactors, AIChE J. 53 (3) (2007) 695-702.

[20] Z. Liu, V. Subramania, M. Misra, Vertically oriented TiO2 nanotube arrays grown on Ti meshes for flexible dye-sensitized solar cells, J. Phys. Chem. C 113 (31) (2009) 14028-14033.

[21] M. A. Eddings, M. A. Johnson, B. K. Gale, Determining the optimal PDMS-PDMS bonding technique for microfluidic devices, J. Micromech. Microeng. 18 (6) (2008) 067001.

[22] T. Saito, T. Iwase, J. Horie, T. Morioka, Mode of photocatalytic bactericidal action of powdered semiconductor $\mathrm{TiO} 2$ on mutans streptococci, J. Photochem. Photobiol., B 14 (4) (1992) 369-379.

[23] K. P. Kühn, I. F. Chaberny, K. Massholder, M. Stickler, V. W. Benz, H.-G. Sonntag, L. Erdinger, Disinfection of surfaces by photocatalytic oxidation with titanium dioxide and UVA light, Chemosphere 53 (1) (2003) 71-77.

[24] K. Sunada, Y. Kikuchi, K. Hashimoto, A. Fujishima, Bactericidal and detoxification effects of $\mathrm{TiO} 2$ thin film photocatalysts, Environ. Sci. Technol. 32 (5) (1998) 726-728.

[25] B. Chen, K. Lu, J. A. Geldmeier, Highly ordered titania nanotube arrays with square, triangular, and sunflower structures, Chem. Commun. 47 (36) (2011) 10085-10087. 
[26] A. Houas, H. Lachheb, M. Ksibi, E. Elaloui, C. Guillard, J.-M. Herrmann, Photocatalytic degradation pathway of methylene blue in water, Appl. Catal., B: Environ. 31 (2) (2001) 145-157.

[27] K. Rajeshwar, M. Osugi, W. Chanmanee, C. Chenthamarakshan, M. Zanoni, P. Kajitvichyanukul, R. Krishnan-Ayer, Heterogeneous photocatalytic treatment of organic dyes in air and aqueous media, J. Photochem. Photobiol., C 9 (4) (2008) 171-192.

[28] H. Jayamohan, B. K. Gale, B. Minson, C. J. Lambert, N. Gordon, H. J. Sant, Highly sensitive bacteria quantification using immunomagnetic separation and electrochemical detection of guanine-labeled secondary beads, Sensors 15 (5) (2015) 12034-12052.

[29] A. Paleologou, H. Marakas, N. P. Xekoukoulotakis, A. Moya, Y. Vergara, N. Kalogerakis, P. Gikas, D. Mantzavinos, Disinfection of water and wastewater by TiO2 photocatalysis, sonolysis and UV-C irradiation, Catal. Today 129 (1) (2007) 136-142.

[30] Y. R. Smith, B. Sarma, S. K. Mohanty, M. Misra, Single-step anodization for synthesis of hierarchical $\mathrm{TiO} 2$ nanotube arrays on foil and wire substrate for enhanced photoelectrochemical water splitting, Int. J. Hydrogen Energy 38 (5) (2013) 2062-2069.

[31] Y. Kikuchi, K. Sunada, T. Iyoda, K. Hashimoto, A. Fujishima, Photocatalytic bactericidal effect of $\mathrm{TiO} 2$ thin films: Dynamic view of the active oxygen species responsible for the effect, J. Photochem. Photobiol., A 106 (1) (1997) 51-56.

[32] Z.-X. Lu, L. Zhou, Z.-L. Zhang, W.-L. Shi, Z.-X. Xie, H.-Y. Xie, D.-W. Pang, P. Shen, Cell damage induced by photocatalysis of TiO2 thin films, Langmuir 19 (21) (2003) 8765-8768.

[33] M. Cho, H. Chung, W. Choi, J. Yoon, Different inactivation behaviors of 
MS-2 phage and Escherichia coli in TiO2 photocatalytic disinfection, Appl. Environ. Microbiol. 71 (1) (2005) 270-275.

[34] H. Chick, An investigation of the laws of disinfection, Journal of Hygiene 8 (01) (1908) 92-158.

[35] H. E. Watson, A note on the variation of the rate of disinfection with change in the concentration of the disinfectant, Journal of Hygiene 8 (04) (1908) $536-542$.

[36] M. Cho, H. Chung, J. Yoon, Disinfection of water containing natural organic matter by using ozone-initiated radical reactions, Applied and environmental microbiology 69 (4) (2003) 2284-2291.

[37] J. Marugán, R. van Grieken, C. Sordo, C. Cruz, Kinetics of the photocatalytic disinfection of Escherichia coli suspensions, Applied Catalysis B: Environmental 82 (1) (2008) 27-36.

[38] Y. R. Smith, A. Kar, V. Subramanian, Investigation of physicochemical parameters that influence photocatalytic degradation of methyl orange over TiO2 nanotubes, Ind. Eng. Chem. Res. 48 (23) (2009) 10268-10276.

[39] T. Zhang, T. Oyama, A. Aoshima, H. Hidaka, J. Zhao, N. Serpone, Photooxidative n-demethylation of methylene blue in aqueous $\mathrm{TiO} 2$ dispersions under UV irradiation, J. Photochem. Photobiol., A 140 (2) (2001) 163-172.

[40] S. Mohapatra, M. Misra, V. Mahajan, K. Raja, A novel method for the synthesis of titania nanotubes using sonoelectrochemical method and its application for photoelectrochemical splitting of water, J. Catal. 246 (2) (2007) 362-369.

[41] S. K. Mohapatra, M. Misra, V. K. Mahajan, K. S. Raja, Design of a highly efficient photoelectrolytic cell for hydrogen generation by water splitting: Application of TiO2-x $\mathrm{C}$ x nanotubes as a photoanode and Pt/TiO2 nanotubes as a cathode, J. Phys. Chem. C 111 (24) (2007) 8677-8685. 
[42] K. Raja, T. Gandhi, M. Misra, Effect of water content of ethylene glycol as electrolyte for synthesis of ordered titania nanotubes, Electrochem. Commun. 9 (5) (2007) 1069-1076.

[43] A. Fujishima, T. N. Rao, D. A. Tryk, Titanium dioxide photocatalysis, J. Photochem. Photobiol., C 1 (1) (2000) 1-21.

[44] P.-C. Maness, S. Smolinski, D. M. Blake, Z. Huang, E. J. Wolfrum, W. A. Jacoby, Bactericidal activity of photocatalytic TiO2 reaction: Toward an understanding of its killing mechanism, Appl. Environ. Microbiol. 65 (9) (1999) 4094-4098.

[45] N. Wang, X. Zhang, Y. Wang, W. Yu, H. L. Chan, Microfluidic reactors for photocatalytic water purification, Lab Chip 14 (6) (2014) 1074-1082.

[46] A. Abarca, P. Gómez-Sal, A. Martín, M. Mena, J. M. Poblet, C. Yélamos, Ammonolysis of mono(pentamethylcyclopentadienyl) titanium(IV) derivatives, Inorg. Chem. 39 (4) (2000) 642-651. doi:10.1021/ic9907718

[47] Y. R. Smith, R. Gakhar, A. Merwin, S. K. Mohanty, D. Chidambaram, M. Misra, Anodic titania nanotube arrays sensitized with Mn-or Co-doped CdS nanocrystals, Electrochim. Acta 135 (2014) 503-512.

[48] R. B. Bird, W. E. Stewart, E. N. Lightfoot, Transport Phenomena, John Wiley \& Sons, 2007.

[49] Y.-Y. Song, F. Schmidt-Stein, S. Bauer, P. Schmuki, Amphiphilic TiO2 nanotube arrays: An actively controllable drug delivery system, J. Am. Chem. Soc. 131 (12) (2009) 4230-4232.

[50] D. C. Duffy, J. C. McDonald, O. J. Schueller, G. M. Whitesides, Rapid prototyping of microfluidic systems in poly (dimethylsiloxane), Anal. Chem. 70 (23) (1998) 4974-4984.

[51] Y. Xia, G. M. Whitesides, Soft lithography, Annual Review of Materials Science 28 (1) (1998) 153-184. 
[52] H.-F. Zhuang, C.-J. Lin, Y.-K. Lai, L. Sun, J. Li, Some critical structure factors of titanium oxide nanotube array in its photocatalytic activity, Environ. Sci. Technol. 41 (13) (2007) 4735-4740.

[53] R. Beranek, H. Tsuchiya, T. Sugishima, J. Macak, L. Taveira, S. Fujimoto, H. Kisch, P. Schmuki, Enhancement and limits of the photoelectrochemical response from anodic TiO2 nanotubes, Appl. Phys. Lett. 87 (24) (2005) 243114-243114.

[54] J. Krỳsa, G. Waldner, H. Měštánková, J. Jirkovskỳ, G. Grabner, Photocatalytic degradation of model organic pollutants on an immobilized particulate $\mathrm{TiO} 2$ layer: Roles of adsorption processes and mechanistic complexity, Appl. Catal., B: Environ. 64 (3) (2006) 290-301.

[55] S.-Z. Chu, S. Inoue, K. Wada, S. Hishita, K. Kurashima, Self-organized nanoporous anodic titania films and ordered titania nanodots/nanorods on glass, Adv. Funct. Mater. 15 (8) (2005) 1343-1349.

[56] M. Pelaez, N. T. Nolan, S. C. Pillai, M. K. Seery, P. Falaras, A. G. Kontos, P. S. Dunlop, J. W. Hamilton, J. A. Byrne, K. O'Shea, M. H. Entezari, D. D. Dionysiou, A review on the visible light active titanium dioxide photocatalysts for environmental applications, Appl. Catal., B: Environ. 125 (2012) 331-349.

[57] H. Aran, D. Salamon, T. Rijnaarts, G. Mul, M. Wessling, R. Lammertink, Porous photocatalytic membrane microreactor (P2M2): A new reactor concept for photochemistry, J. Photochem. Photobiol., A 225 (1) (2011) 36-41.

[58] E. K. Sackmann, A. L. Fulton, D. J. Beebe, The present and future role of microfluidics in biomedical research, Nature 507 (7491) (2014) 181-189. 


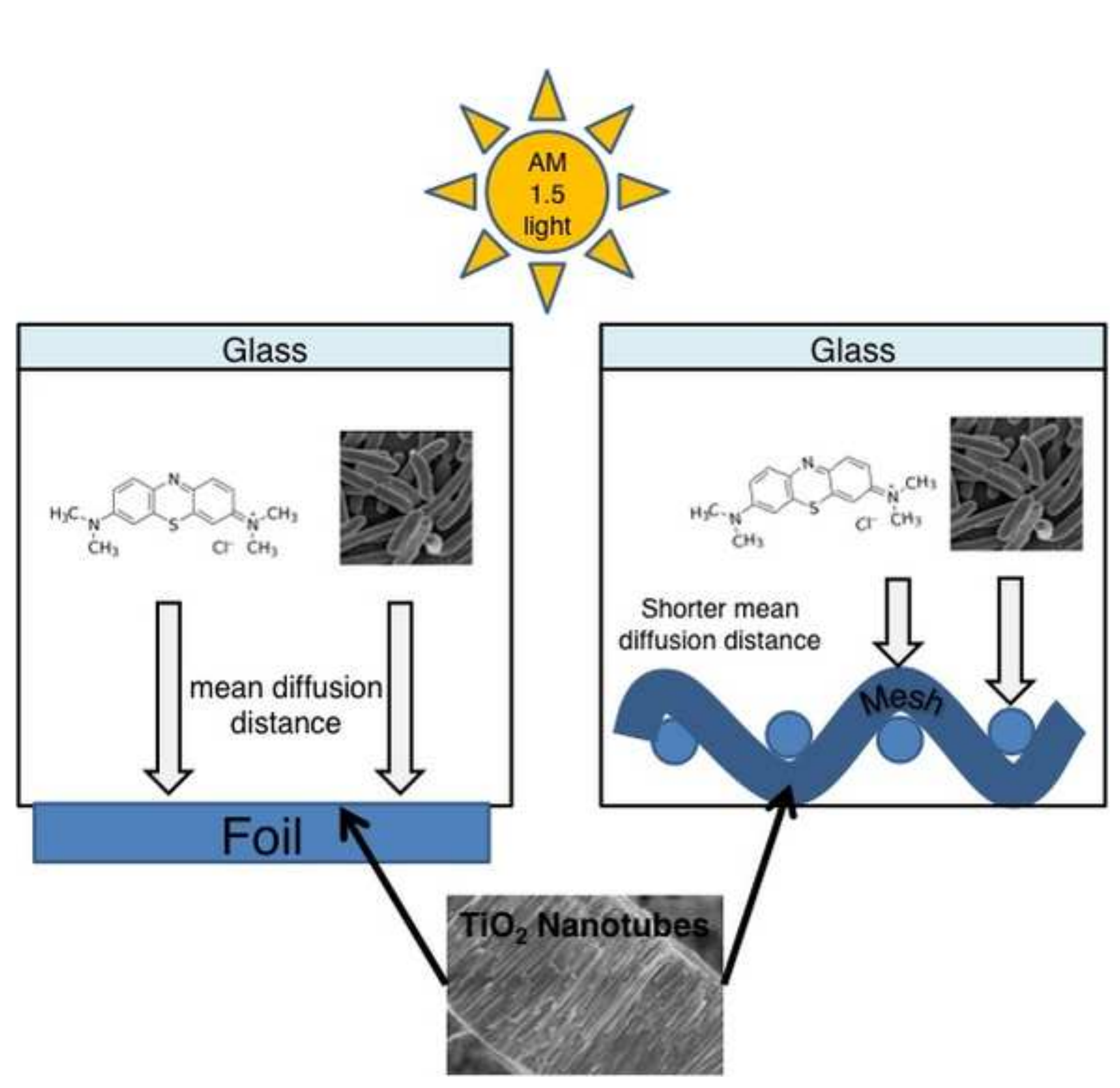

